\title{
Cueva, piedra y adobe. La comprensión quechua del cambio social por medio de la casa
}

\author{
Óscar Muñoz Morán \\ Depto. de Historia de América II (Antropología de América) \\ Universidad Complutense de Madrid \\ oscarmmoran@gmail.com
}

Recibido: 9 de enero de 2012

Aceptado: 27 de febrero de 2012

\section{RESUMEN}

Los habitantes de la comunidad quechua de Coipasi (Potosí, Bolivia) narran el paso del tiempo y el desarrollo de la comunidad por medio, entre otras cosas, de la interpretación que hacen de los diferentes lugares que, dentro de su territorio, se han habitado a lo largo de la historia. En concreto, en este artículo, se analizará el importante significado que parecen tener las estructuras habitacionales y los materiales de los que están construidas, señalando un claro progreso desde la piedra o la cueva en el pasado más remoto, a los materiales modernos de la actualidad.

Palabras clave: Bolivia, quechuas, pasado, arquitectura, vivienda, desarrollo social.

\section{Cave, Stones and Adobe. Quechua Understanding of Social Change through the House}

\begin{abstract}
Coipasi is a Quechua community. Its people tell the time and the community's development through the interpretation of different places, within their territory, that have been occupied throughout history. In this paper, I discuss the important meaning that appear to have housing structures and materials that are made, indicating a progress from the stone or the cave in the remote past, to today's modern materials.
\end{abstract}

Key words: Bolivia, Quechuas, past, architecture, dwelling, social progress.

Sumario: 1. Introducción. 2. Los primeros asentamientos en el tiempo antiguo. Las no-casas. 3. Los coipaseños actuales. Casas de piedra, adobe y cemento. 4. Reflexiones finales. 5. Referencias bibliográficas.

En el extremo oriental del altiplano andino del sur de Bolivia, la población quechua de Coipasi consigue ubicarse en el mundo que habita por medio no únicamente de la definición del territorio donde residen actualmente, sino también por toda una serie de lugares, bien identificados, donde habitaron con anterioridad ya sean sus antepasados directos o cierta humanidad tan lejana en el tiempo que no se identifican con ella. En este texto etnográfico veremos cómo los coipaseños se definen en relación con estos lugares, lo que en ellos sucedió, el tiempo en el que los ubican y el tipo de construcciones que los caracterizan. De hecho, aquí se quiere privilegiar el análisis de esto último, pues en el trabajo de campo se presentó como un elemento esencial por medio del cual los locales entienden el tiempo y, especialmente, el progreso y desarrollo comunitario. 


\section{Introducción}

Los habitantes de los Andes no tienen bien definido y delimitado el espacio habitado. Sí lo que comúnmente conocemos por vivienda o casa, pero no tanto aquello que podemos considerar el pueblo. Como bien han demostrado los estudios clásicos de John V. Murra (1975; 2002), el hombre andino ha tenido siempre diferentes lugares de hábitat, donde pasaba temporadas específicas del año e, incluso, donde situaba a diferentes miembros del ayllu. Estos pisos ecológicos -archipiélago vertical- estaban determinados por las labores agrícolas o ganaderas que en ellos se desarrollaban. Hoy en día, todavía persiste la posesión de diferentes tierras en distintos pisos ecológicos del territorio, pero la mayor parte de la población indígena se adscribe a un único pueblo como lugar de residencia.

De todas formas, incluso estos pueblos no son, ni mucho menos, uniformes ni se encuentran bien delimitados. No suele existir (excepto en el caso de grandes poblaciones producto de las reducciones de Francisco de Toledo en la segunda mitad del siglo XVI) un núcleo bien definido y una continuidad habitacional. Más bien al contrario. Los pequeños pueblos indígenas andinos son agrupaciones de casas dispersas, en muchos casos con grandes espacios de separación entre ellas y con un elemento que resulta esencial para comprender gran parte del imaginario local respecto a su territorio: la alternancia de lugares habitados con lugares que podemos considerar como liminales, de conexión con el interior de la tierra y con las entidades que en ellos habitan.

En último lugar de esta «jerarquía» territorial, se encuentra la casa o el hogar familiar. No interesa en este trabajo la definición etnográfica de las características sociales de la misma, que han hecho otros colegas; pero sí ciertos aspectos de las materiales y simbólicas ${ }^{1}$. Porque, como es de imaginar, para el hombre andino la casa es sinónimo del lugar donde ésta existe o existió, donde se encuentra o encontraba un «pueblo».

Por tanto, veremos cómo en la comunidad quechua de Coipasi, entienden que el conjunto de casas actuales que hoy denominan pueblo, no es el primero, sino que anteriormente existieron otros que se conocen no únicamente por las historias orales que los significan, sino también por las viviendas -y sus características- que a ellos se asocian.

La casa como recurso mnemotécnico es algo que ya ha sido estudiado en los Andes, no únicamente en la actualidad (Arnold 1998: 38), sino que el propio Guaman Poma presentaba las construcciones como uno de los principales elementos para datar las diferentes edades entre los indios del Perú. En su análisis de las cuatro edades existentes (Uariuiracocha Runa, Uari Runa, Purun Runa y Auca Runa) plantea las condiciones de las viviendas donde habitaba cada humanidad, como uno de sus rasgos culturales más significativos ${ }^{2}$. En la primera edad los pacarimoc runa «no sabían

1 Existe una amplia literatura antropológica sobre la incidencia social de la construcción de las casas tanto entre aymaras como quechuas (Abercrombie 2006: 414 y ss; Arnold 1998; Gose 1991; Platt 1986; Urton 1988), así como del aspecto etnográfico descriptivo de las estructuras habitacionales (Ochoa 1976; Ravines 1978).

2 Para un análisis etnohistórico de estos periodos, acúdase a los trabajos de Bouysse-Cassagne (1987; Bouysse-Cassagne y Harris 1987). 
hacer casas, vivían en cuevas y peñascos» (Guaman Poma 1980: 39), es decir, todavía no habitaban en policía, ni poseían un orden. Los hombres de la segunda edad, la Uari Runa, tampoco tenían casa, sino que vivían en «unas casitas que parecen horno que ellos llamaban pucullo» (Guaman Poma 1980: 42), como se puede apreciar perfectamente en la ilustración 53 de su obra. Respecto a lo que dice de la tercera edad, es donde más parecidos encontraremos con este trabajo: los hombres de la Purun Runa, «comenzaron a poblarse en tierra baja y de buen temple y caliente y edificaron casas de pucullo, de allí comenzaron alzar paredes y cubrieron casas y cercos, y reduciéronse, y tuvieron plaza, aunque no supieron hacer adobes, sino todo era de piedra» (Guaman Poma 1980: 45; cursivas mías). Por último, en la edad Auca Runa, debido al periodo bélico en el que se encontraban, los hombres tuvieron que construir fortalezas llamadas pucara, dentro de las cuales iban las casas (Guaman Poma 1980: 48).

Lo que me interesa resaltar aquí no es la coincidencia en la lectura del pasado con las poblaciones andinas actuales, y tampoco la coincidencia en la interpretación del tipo de vivienda y sus materiales -que por otro lado, veremos que sí es semejante en algunos casos-, sino la idea del uso de la casa como recurso mnemotécnico e interpretativo del pasado. La vivienda como representación del tiempo, de su paso y del acontecimiento histórico. Guaman Poma utiliza la descripción de las casas de las diferentes humanidades para significarlas en el texto, para dotarlas de un contenido semiótico que pueda ser comprendido por la sociedad del momento. La importancia que le concede a las viviendas como descriptoras de las diferentes edades, se puede observar en que todas aparecen (o no, porque no existían, como sucede en la primera) en las ilustraciones que acompañan a su obra. En éstas se puede apreciar perfectamente el tipo de vivienda y el material con el que está construida (Figura 1).

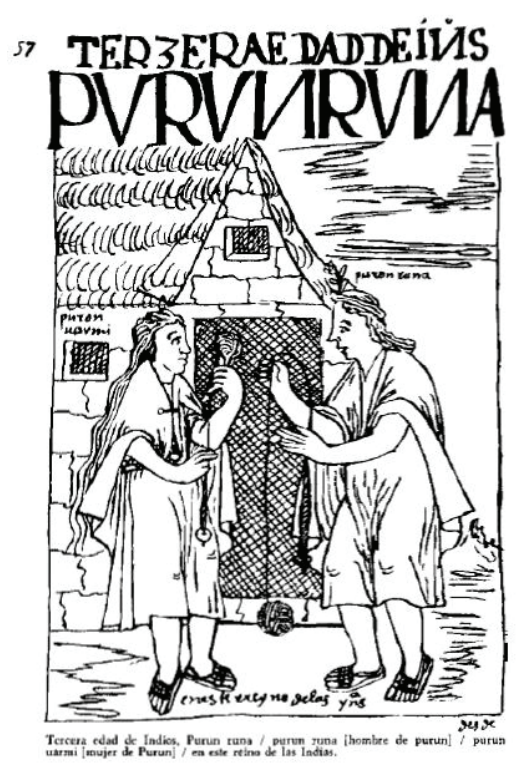

Figura 1: La tercera edad o Purun Runa de Guaman Poma con el tipo de casa que la caracteriza. 
En la comunidad de Coipasi, como intentaré mostrar, la forma de las casas de tiempos pasados y contemporáneos, los materiales usados y sus estructuras, así como la labor humana a la hora de construirlas, son hoy día un argumento esencial sobre el que el coipaseño habla del progreso y desarrollo social comunitario ${ }^{3}$.

\section{Los primeros asentamientos en el tiempo antiguo. Las no-casas}

En Coipasi se reconocen cinco lugares de asentamiento humano dentro de su territorio, aunque normalmente en las narraciones se simplifique en tres, como nos dice don Guillermo Huaranca4: «la primera ciudad dicen que era allá dicen [Laqaya]. Y la segunda ciudad dice que era allí arriba [Churumayo]. Ahora es la tercera aquí». De ellos, dos son considerados como propios (Churumayo y Coipasi actual), es decir, que han sido habitados por el grupo actual, y tres como ajenos (Collpa Wasi, Laqaya y Vizcachas Wasi), cuyos pobladores, aunque ligados de una forma u otra a los coipaseños contemporáneos, no lo hacen por una filiación directa, sino por relaciones de diferentes tipos, como veremos a continuación.

Los tres últimos, Collpa Wasi, Laqaya y Vizcachas Wasi, están asociados a un tiempo tan lejano y distante (el unay timpu o «tiempo del diluvio») que ni siquiera se puede ubicar de una forma correcta. Aun así, los coipaseños hacen un esfuerzo por datarlos cronológicamente: probablemente antes de Cristo. De los tres, el que se reconoce como más antiguo es Laqaya, el asentamiento chullpa. En la literatura etnohistórica y antropológica de la región, los chullpas son mencionados como los miembros de una humanidad primigenia, que según la concepción local habitaron la tierra en el tiempo más antiguo, antes incluso de la aparición del Sol. Son reconocidos como seres de costumbres salvajes y paganos, aunque humanos. Su desaparición es precisamente el resultado del surgimiento del Dios-Sol, que los quemó y secó en las casas que habían hecho para protegerse de él (Abercrombie 2006; Allen 1994; Dillon y Abercrombie 1988; Gil 2005; Rasnake 1988; Wachtel 2001).

En Coipasi esta narrativa varía considerablemente. Para ellos, los chullpas, al menos aparentemente, no son seres salvajes e incivilizados, pues como me dijo un comunario, «eran como nosotros». Se basan en dos argumentos principales para esta afirmación: el primero es que vivían en un pueblito o llajta, ubicado precisamente en terrenos del paraje Laqaya; el segundo es que, según afirman, hacían sus propias misas y tenían sus sacerdotes como atestigua la presencia del denominado Tata Cura.

3 Coipasi es una comunidad quechua hablante que se encuentra a unos 65 kilómetros de la ciudad de Potosí (sur de Bolivia). Cabecera de cantón y de ayllu que llevan el mismo nombre, forma parte del municipio de Chaquí, una de las entidades sociales y geográficas con mayor tradición histórica en la región. Tiene un número aproximado de 1000 habitantes, aunque muchos de ellos no residen en el pueblo. La migración es un claro marcador cultural en la comunidad, pues hoy en día resulta muy complicado encontrar jóvenes entre los 18 y los 45 años. La mayor parte de ellos son migrantes de no-retorno en Argentina.

${ }_{4}$ Como digo, Coipasi es la cabecera también del ayllu que lleva su mismo nombre. Dicho ayllu mayor está dividido en dos menores: Ura Coipasi (Coipasi de abajo) que comprende las comunidades de Chaquí Baños y Qollpa Pampa; y Pata Coipasi (Coipasi de arriba) que comprende a la misma Coipasi, más Phalapaya, Villcamayu y El Palomar. La autoridad máxima es el kuraka de Coipasi, aunque cada uno de los ayllus menores tiene su propio kuraka. Este artículo se limita al estudio de la comunidad de Coipasi. 
Brevemente señalaremos que el Tata Cura es una gran piedra que sobresale de la tierra en mitad de una cancha. Se afirma de él que era un cura que estaba dando misa en ese lugar cuando llegó el diluvio, quedando entonces petrificado. Desde ese momento, el Tata Cura se ha convertido en piedra de culto para los coipaseños, aunque, según se comenta, hace ya muchos años que éste no se práctica ${ }^{5}$. No obstante, todos dicen temer y respetar al Tata Cura, pues si en el algún momento muestras signos de desprecio o incredulidad hacia él, se te presentará en sueños para anunciarte un accidente próximo.

Respecto al pueblo chullpa, los coipaseños afirman que, aunque hoy en día ya no hay estructuras que ayuden a identificar dicho asentamiento, sí hay restos óseos que hablan del mismo. Según los pobladores de Coipasi, en realidad los chullpas como tales ${ }^{6}$ son principalmente los huesos enterrados en el lugar. No obstante, hay otros parajes en la comunidad que son chullpa, porque en ellos han aparecido huesos, pero, al contrario que Laqaya, no son considerados pueblos. ¿Dónde está entonces la diferencia? Principalmente en que los comunarios hablan de que en otro tiempo aquí sí hubo estructuras habitacionales e, incluso, unos pocos afirman que las que hoy se pueden ver son todavía los restos de aquellas.

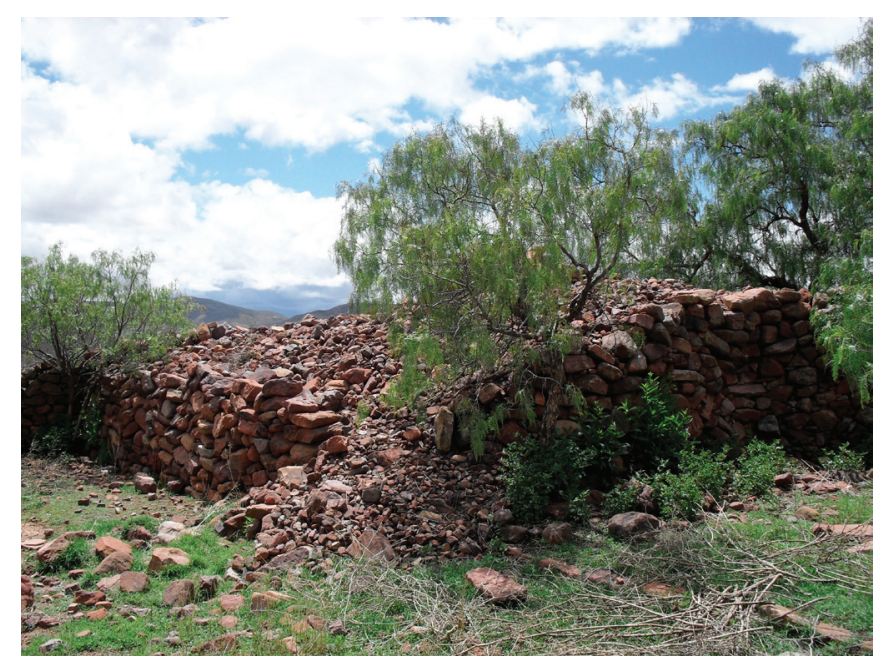

Figura 2: Restos de una antigua casa en el terreno de la L'akaya.

5 El Tata Cura podría corresponder a lo que Astvaldsson (2000) ha denominado en los Andes como wak'a, es decir, monolitos o formaciones rocosas identificadas con seres protagonistas del pasado y que se considera que tienen un cierto poder y, por tanto, se les rinde culto. El culto al Tata Cura todavía no he podido registrarlo, pero el resto de las características sí parece compartirlas con esa idea de wak'a.

6 El término chullpa puede tener otros significados dependiendo de quién lo use: literalmente en quechua o aymara significa «momia», acepción que también es usada por los pobladores locales; para los arqueólogos los chullpas o chullparios son las estructuras funerarias incas y preincas que se encuentran por gran parte de la puna andina y que, por otro lado, son donde se suelen localizar las momias; incluso en la comunidad peruana de Sonqo, C. Allen (1994: 92) registró que los chullpas o machukuna reviven en las noches de luna llena, así como también se habla de los machukuna para referirse al negativo de una fotografía, a las voces de la radio o una estatua de piedra. 
Estas estructuras son anchos muros de piedra sin revocar que delimitan terrenos dentro de Laqaya; e, incluso, una pequeña estructura en forma de casa, que se encuentra en un extremo del paraje, también con las mismas características arquitectónicas (Figura 2). Tuve la sensación de que los comunarios guardan un cierto respeto hacia esta construcción, al no saber su origen. No pueden decir que sean chullpa, pero tampoco desmentirlo. No obstante, cuando se pregunta por el pueblito chullpa, se afirma que ya no está, desapareció y no queda nada de él excepto los huesos.

La narrativa cuenta que ese pueblo vivía ahí antes de Cristo cuando de repente vino el diluvio de los cuarenta días y las cuarenta noches ${ }^{7}$. Inundó toda la pampa haciendo desaparecer incluso a los animales y acabando con prácticamente toda la población chullpa ${ }^{8}$. Sólo unos pocos consiguieron escapar y refugiarse en Vizcachas Wasi. Este lugar es una qaqa o gran saliente de roca existente en el cerro Kamachita, cercano a Laqaya. En esa qaqa existe una pequeña oquedad que se supone es el acceso al interior del cerro donde se refugiaron los chullpas (Figura 3). Las pruebas de que éstos habitaron este lugar son dos. Por un lado las pinturas que dejaron en las paredes y que hoy prácticamente han desparecido'; nos dice don Fermín Relos al respecto, «de todos modos para este lado, hay unas piedritas, que hay unos dibujos. Tipo como sangre, que no se le borra». Y, por otro lado, los khawas o despensas de alimentos que hay construidas entre las paredes del Vizcachas Wasi.

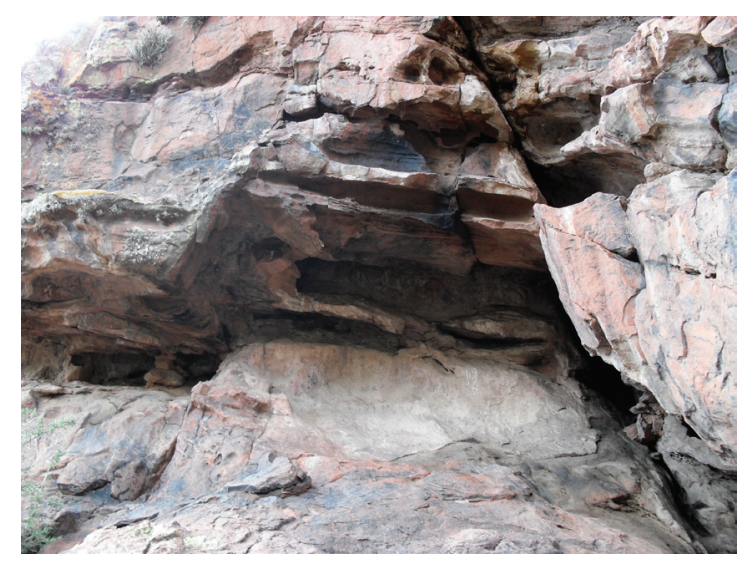

Figura 3: Wizcachas Wasi: lugar de acceso al interior y, a la izquierda de la imagen, las khawas.

\footnotetext{
7 No es el momento de entrar aquí a analizar la influencia de nuevas ideas en las transformaciones de la narrativa histórica local, pero es evidente que en ésta que estamos viendo hay un marcado giro bíblico producto, en primer lugar, de la enseñanza de los Evangelios en las Escuelas de Cristo desde mediados del siglo pasado - de las que hablaremos más adelante- $\mathrm{y}$, más recientemente, de la corriente evangelista que siguen casi la mitad de los comunarios. De hecho, existe una cierta disputa entre los coipaseños sobre si el diluvio fue de agua o de fuego, ambos aparecidos en diferentes pasajes bíblicos.

8 La mayoría de los lugares que de una forma u otra son objeto de narraciones sobre sucesos extraños, tiempos lejanos, antepasados o situaciones relacionadas con el espacio liminal, se sitúan en la pampa, que no podemos olvidar que, tanto para aymaras como para quechuas, es una especie de territorio yermo, relacionado con el tiempo puruna o más antiguo, caracterizado por lo salvaje y la oscuridad (Bouysse-Cassagne 1987: 191).

9 Está comprobada la existencia de un corredor en la zona en el que la abundancia de los lugares con pinturas rupestres los ha convertido en liminales, de conexión entre mundos andinos (Cruz 2006).
} 
Un comunario comentaba respecto al lugar y sus habitantes que «era la casa de los chullpas o después de los chullpas, qué sería. Y aquí vendrían, aquí. ¿Qué harían aquí? En este peñasco... No tengo la menor idea si hallara la población». Es evidente que entre los coipaseños el lugar parece crear cierta inquietud, al mismo tiempo que curiosidad. Por un lado, no se sabe exactamente cómo consiguieron vivir allí, pues por la pequeña apertura en la roca dicen que solo pueden pasar «enanos» ${ }^{10}$. Hay curiosidad por saber qué habrá dentro, y se habla incluso de «grandes salones» donde vivían. Por otra parte, el Vizcachas Wasi, la qaqa, no es otra cosa que un lugar liminal que conecta el interior de la tierra o ukhupacha (con todos los atributos que se asocian a éste, como el hábitat del supay o diablo, entre otros) con la superficie, donde viven los runas u hombres, el kaypacha (Cruz 2005 y 2006).

¿Qué sucedía entonces, en este chullpa timpu, con los actuales coipaseños? ¿Existía el asentamiento donde hoy se localizan o alguno parecido? La respuesta parece ser claramente que no, pero en la interpretación local del pasado sí aparece un nexo de conexión entre ese tiempo y en el que ya aparecieron ellos. Ese puente se denomina Collpa Wasi.

Al preguntar a los coipaseños por el origen del nombre de la comunidad, todos, sin excepción, narran la historia de collpa wasi. Collpa (o coipa, como también se puede escuchar en el pueblo) wasi quiere decir literalmente casa (wasi) salada o salitrada (qollpa). Coipasi viene por una derivación de collpa wasi, que muchos comunarios atribuyen a los españoles. Se explica que desde tiempos antiguos, por un camino existente en la pampa cercana a Coipasi, pasaban caravanas de llamas que trasladaban sal de la región de Uyuni al resto del territorio boliviano. Cercano al actual asentamiento, había un lugar donde los llameros «pasaban nada más. Nada más que se alojaban un rato, una parte retirada, ¿no? Se alojaban, descansaban un día, una noche, seguían sus caminos» (Fermín Relos Alaca). Es decir, en ese lugar tenían por costumbre descansar, y allí dejaban sus fardos de sal. De ellas se caería la sal, que se filtraba a la tierra, convirtiéndose en un lugar qullpa ${ }^{11}$. Aunque algunos afirman que realmente allí se construyó una casita de sal ${ }^{12}$, la mayor parte de ellos no hablan de estructura alguna y debemos interpretar wasi, por tanto, simplemente como lugar de descanso. No se sabe si en algún momento hubo una casa. En el caso de que la hubiera ya no queda resto de ella, «Collpa Wasi es una parte que no hay nada. No hay nada, ni una casa». De hecho, el lugar hoy en día, ni siquiera se conoce con ese nombre, pero sí ha quedado registrado el topónimo histórico en la memoria coipaseña.

10 Es importante señalar que en Coipasi no se piensa que los chullpas fueran enanos, sino más bien todo lo contrario: gigantes; ello se debe al tamaño enorme de los huesos encontrados en la pampa, que ahora muchos ya (después del paso de los paleontólogos) identifican con dinosaurios. Sea una caracterización u otra, lo que parece evidente es que también en Coipasi se tiene la idea de una desproporción corporal de los habitantes antiguos, como sucede en gran parte del mundo amerindio (Gutiérrez 2010: 22).

11 Según el Diccionario de la Real Academia de la Lengua Española, la segunda acepción de «salitre» es «sustancia salina, especialmente la que aflora en tierras y paredes». Hoy en la comunidad se dice que la prueba de esta salinidad es que las ovejas o las cabras se acercan hasta allí para lamer la tierra.

12 «Collpa Wasi porque, hicieron, pues una casita con pura sal. Ves como hay paquetito, así, lo apilaron e hicieron dicen. Entonces, por esa razón le dijeron Collpa Wasi» (Fermín Relos). Aunque más adelante el mismo Fermín nos dice «Los campesinos ahí, como digamos, hay una lugar campo, como para alojar a las llamas. Entonces descargaban la carguita, empezaban a dormir y seguían el viaje. Por eso desde antes, habrán nombrado, ellos mismos eso, Coipa Wasi». 
Collpa Wasi es el lugar (y el acontecimiento asociado a él) de transición entre el tiempo antiguo y el actual (runa timpu). Es así en parte porque los llameros de sal han estado transitando por el comentado camino hasta los años 70 del siglo pasado ${ }^{13}$; y en parte porque a la pregunta de si existía el actual asentamiento cuando Collpa Wasi, todos afirman que sí. Es evidente que detrás de esta afirmación hay una datación atemporal del acontecimiento. Es decir, si han existido llameros hasta hace relativamente poco tiempo, y continuaban usando Collpa Wasi como lugar de descanso, es normal que se piense en una coexistencia de los dos asentamientos casi desde siempre.

Resulta interesante señalar, como hemos visto en este epígrafe, que los tres lugares analizados han estado habitados por otros, aunque chullpas y llameros tienen connotaciones y características diferentes. Unos son una humanidad ya extinta por el diluvio; los otros runas, u hombres actuales, aunque de otra región del país. Eso sí, los dos de un tiempo antiguo, que no parecen haber convivido. Como afirma Gregorio Vargas, Collpa Wasi

«Después de los chullpas ha sido. Dicen, ¿no? ${ }^{14}$ Porque, bueno...también habría sido desde muy antes por algo que el llamerito, porque antes que vengan los españoles existieron las poblaciones y habían campesinos que caminaban. Y entonces esos, sabrían dejar su salita y todo».

Y los tres asentamientos se caracterizan por la inexistencia de construcciones. En Laqaya se habla de todo un pueblo, incluso un pueblo grande. En Vizcachas Wasi de un asentamiento interior también grande, incluso con sus despensas de alimentos. En Collpa Wasi, de un indeterminado lugar de descanso de viajeros. Todos ellos hablan, por tanto, de lugares de hábitat, pero en ninguno se tiene la certeza de cómo eran las estructuras donde habitaban. Son las no-casas ${ }^{15}$, es decir, viviendas que no se sabe seguro de su existencia, pero se presupone. En muchos casos, ni siquiera se sabe de su estructura, pero se especula sobre la misma: construcciones de piedras en Laqaya;

13 Don Valeriano Huaranca me narra cómo era el transito de llamas, hablando de tiempos más cercanos, pero dentro de una conversación sobre Collpa Wasi: «Sí lo veo todavía. Por allá claro, por esa loma nomás. Se ponen a dormir...venían a ver, ¿cómo se llama?, los 15 de mayo, por ahí ya sabían venían de ahí por acá. Desde allá volvían, más o menos, dentro de un mes. Sabían llevar sal, hacían para cambiar con trigo. Porque de Potosí más allá, parece que no produce na’. Solamente llama, se mantiene por ahí, ¿¿no? Entonces, con eso salían ellos y parecen que...con sal iban, así. Cada llama llevaba dos, así de sal. Así sabían ellos. Después volvían con trigo, con maíz, se iban también. Pero ahora, como hay movilidad, parece que andan en movilidad. Luego así, porque ellos siempre se mantenían así. Traían sal...así pasó. Y aquí también sabían traer sal, sabían cambiar con maíz, y así».

${ }^{14}$ Como señala el antropólogo Vicent Nicolas, los quechua hablantes utilizan la palabra nin (dicen), constantemente en sus narraciones cuando están hablando de un tiempo no vivido. Con ella aseguran la transmisión oral y resaltan la temporalidad del acontecimiento (2004: xxiii).

${ }_{15} \mathrm{La}$ aplicación de esta terminología sigue la línea de otros autores que anteriormente lo han hecho para diferentes estructuras culturales. Por ejemplo, los famosos «no lugares» de Marc Augé (1998) o los «no-eventos» de Ann L. Stoler (2009). Ambos autores, al igual que la idea que sostengo yo aquí para las no-casas, indican que existen referentes culturales, ya sea materiales, cognitivos o incluso estructuras, que se caracterizan por tener todos los atributos necesarios para definirlos como tal, pero que por unas razones u otras no alcanzan a serlo. Por ejemplo, los no lugares son aquellos creados por la modernidad donde, pese a producirse el tránsito constante de personas, no consiguen crear lazos y redes sociales estables (Augé 1998). Los no-eventos son las políticas o acciones que fueron pensadas y realmente interiorizadas por un grupo o sector del mismo, pero que nunca fueron puestas en práctica (Stolen 2009: 106-108). 
cuevas no conocidas e inaccesibles en Vizcachas Wasi; y una posible casa construida de sal en Collpa Wasi.

En todos los casos, las estructuras reflejan una serie de características que las ponen en común. En primer lugar, su vulnerabilidad. Todos ellas, si existieron, han sido destruidas. Todas han desaparecido sin dejar casi rastro. Y digo casi porque todas han dejado alguno: estructuras indefinidas de piedras; pinturas y khawas en las paredes de la qaqa; sal en el suelo que es lamida por los animales. Pero ninguno de estos restos es suficiente como para hablar con seguridad de viviendas. En segundo lugar, que todos ellos resultarían difícilmente habitables para los coipaseños actuales. Los materiales de construcción (piedras, roca natural y sal) no son considerados civilizados y dentro de los cánones de progreso de los que hoy presumen los comunarios. Por tanto, nos encontramos ante no-casas. No existen, pero se sospecha que en un tiempo existieron, aunque no se está seguro de ello. En el caso de que sea cierta su existencia, tenían unas características arquitectónicas muy alejadas de las actuales. Son el fiel reflejo de otros tiempos, de otros hombres e incluso humanidades, de otros acontecimientos y de otros estados de desarrollo que están ya superados.

\section{Los coipaseños actuales. Casas de piedra, adobe y cemento}

Como ya he mencionado, la interpretación local afirma que Collpa Wasi convivía con el núcleo actual. Más correctamente, habría que decir, que con los coipaseños actuales. Se mencionó al principio del artículo que existían dos asentamientos considerados como propios, es decir, donde vivió y donde vive el grupo actual. En realidad, el que se entiende como más antiguo, como el primero, todavía está en uso y se encuentra dentro del propio pueblo contemporáneo.

La comunidad de Coipasi está hoy dividida en tres secciones conocidas como (de sur a norte) Chawpi Kalle, Plaza Pata y Kelaque. Entre las dos primeras se encuentra Churumayo, una sección en las faldas de un cerro, que hoy en día sólo está habitado por un par de familias.

Churumayo aparecía en las conversaciones cuando se preguntaba por el pueblo antiguo, por aquel que estaba cuando los llameros de sal. Te hablaban de un asentamiento «allá en el cerro», donde hay casas de piedra. Incluso en algunas ocasiones se habló del pueblo de los inkas, pero lo habitual es que se dijera que era el pueblo del «tiempo de los abuelos» ${ }^{16}$. A la pregunta de dónde estaba el pueblo a la llegada española, don Valeriano Huaranca responde: «Estaban aquí, ya había gente. En cerrito, toda esa parte. Acá abajo... así cuando ya han multiplicado más, han bajado para acá»». Esta afirmación refleja tres datos que considero importantes: primero, el

16 En quechua, «tiempo de los abuelos» o «desde los abuelos» se dice abuelomantapacha, que refleja una temporalidad no bien definida. El «tiempo de los abuelos» no siempre quiere decir que literalmente corresponda al vivido por los abuelos de los narradores, sino que puede referirse a un tiempo lejano, aunque ya correspondiente al grupo. Como dice la forma quechua: abuelo ya prescribe una filiación directa, es decir, de esta humanidad, no de los chullpas, por así decirlo; manta, es una partícula que en quechua, en este caso, refleja distancia indeterminada, ya sea temporal o espacial; pacha es la partícula usada directamente para indicar temporalidad (aunque también se puede aplicar para señalar espacio). 
asentamiento a la llegada española era el Churumayo («en cerrito»); segundo, este lugar y sus gentes son consideradas parte del actual grupo («estaban aquí, ya había gente»); tercero, posteriormente, cuando fueron más, tuvieron que ampliar hacía «acá abajo», es decir, el actual núcleo. Éste está todo concentrado en el límite con la pampa, aunque sí es cierto que muy cercano a los cerros. Justo más allá de estos límites, en un extremo del pueblo, se extiende el Churumayo sobre un pequeño cerro: «antes la gente, que vivían más en la parte, más al rincón al cerro, en el rincón» (Valeriano Huaranca).

El lugar conocido como Churumayo es una pequeña extensión de casas en ruinas, todas de piedra, donde se supone que se habitó por primera vez (Figura 4). Las personas que todavía viven allí, están situadas, en realidad, en uno de los extremos de lo que ellos llaman Churumayo. No se identifican con el lugar y dicen vivir en el Yawakata, que es el nombre que recibe el cerro. Junto a este, hay otro cerrito pequeño donde se pueden ver terrazas de cultivo que los coipaseños afirman eran las usadas por los antiguos habitantes de Churumayo. Sí es importante señalar que se dice que el Churumayo estaba habitado hasta hace poco tiempo, tal vez unos setenta años, pues los mayores dicen recordar ver gente viviendo en él cuando eran niños, e incluso el que parte de las celebraciones de la fiesta de San Pedro se hicieran en ese lugar ${ }^{17}$. Desde luego, como observador, el estado en el que se encuentran las ruinas de la antigua población hace pensar en un abandono muy distante.

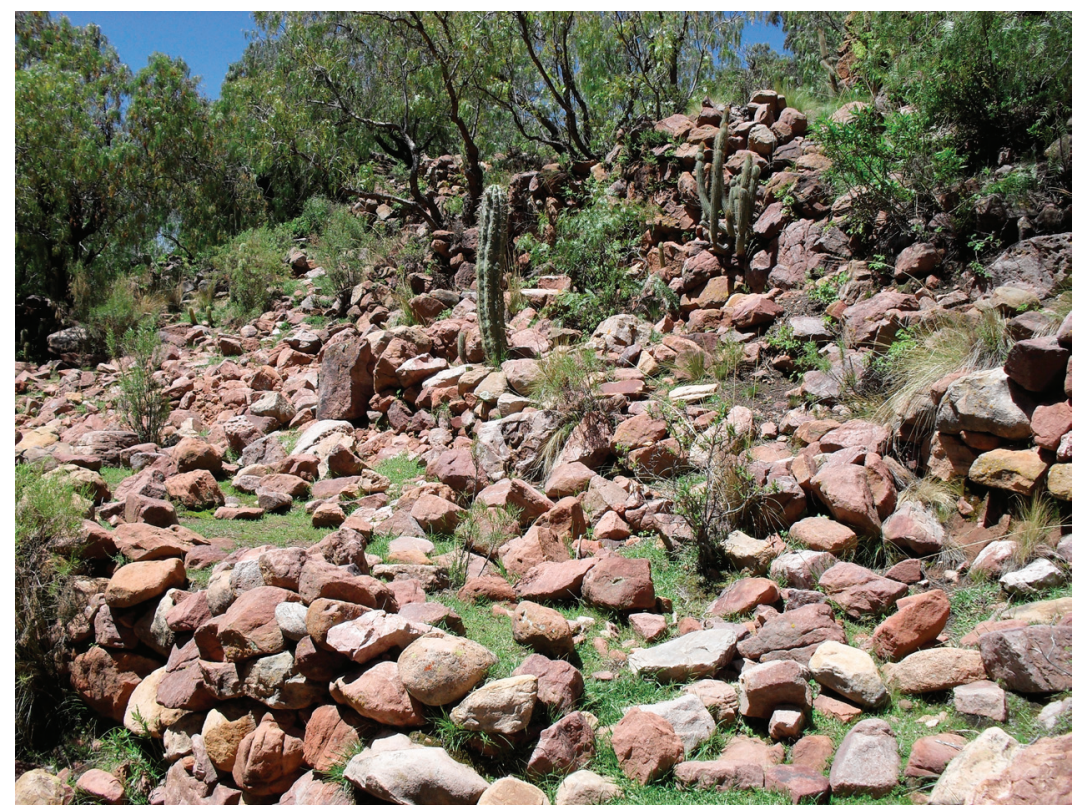

Figura 4: Las piedras que señalan los restos de las antiguas casas del Churumayo.

17 En la comunidad, como veremos más adelante, hay dos fiestas importantes: la patronal de San Pedro y la civil del 9 de mayo, conocida como «aniversario de la escuela». 
Al preguntarle a Valeriano Huaranca sobre la datación del Churumayo, me dice:

«Antes. Sí porque, seguramente aquí han llegado con trigo, digamos. Aquellas veces cuando estaban viniendo, de allá, parece que andaban...porque antes de los españoles, parece que se llamaba Collasuyu, ¿no ve? Collasuyu, todo Bolivia. Entonces, ¿no siente que los incas trajinaban bien?, creo que estaban bien organizados. Entonces en esa razón, parece que claro...esto no había nacido todavía, no había nada, no había nada entonces, de allá, no sé, sea del lado de La Paz, donde había gente, parece que han salido en tribus. En tribus, porque como había allá en el Churumayo agüita, se han poblado en ese cerro ${ }^{18}$. Se han poblado, entonces como está vacío éste, fundacionó [sic]. Se han puesto a vivir aquí. Y por esa razón, aquí cerquita está el cementerio. Aquí cerquita está. Si hubieran hecho todo la casa por acá (...) Si hubiera sido casa aquí, entonces, más abajo hubieran hecho el cementerio. Más abajo seguramente hubiera...ya nuestros padres pensaron, este cementerio, lleva más abajo».

El argumento del cementerio es uno de los más recurridos por los coipaseños para señalar al Churumayo como el primero y único asentamiento de tiempos anteriores. El actual panteón comunitario se encuentra emplazado en mitad del pueblo. Se dice que eso no es lo habitual, que debe estar alejado, pero como fue creado por los habitantes del Churumayo, para ellos sí estaba apartado, pero para el actual asentamiento no.

Otra forma para hablar del Churumayo como un lugar antiguo, es el material de construcción de sus casas. Eran viviendas enteramente de piedras, cuyos restos riegan hoy absolutamente todo el cerro ${ }^{19}$. Don Valeriano Huaranca al preguntarle por primera vez por el lugar, me dijo:

«Ese parece piedras, casitas que tenían. Ahora han vivido, tres o cuatro familias, en esa parte».

\section{Y el kuraka Tata Guillermo ${ }^{20}$,}

«de mi papá, sus abuelos, nuestros abuelos pues. Entonces sí....vivían pues así, no conocían. Bueno, todavía están un poquito mejor. Antes no. Vivían así, se habían hecho unas casitas de piedra. Así como revolcaó con barro. Pero la gente antigua dicen que era pues, altotes, dicen que eran pues, de muchos huesos. Y habían puestos sus casitas de piedras, así de grandes...».

Es decir, las construcciones parecían ser ciertamente arcaicas. De piedra o barro mezclado, en la ladera de un cerro. Restos que todavía son visibles y que los coipaseños te llevan a ver con entusiasmo.

18 No es habitual -aunque cada día más frecuente- encontrar entre la memoria campesina un conocimiento histórico de este tipo. El Collasuyu o la emigración de esas tribus (que puede coincidir perfectamente con la extensión aymara o la inca posterior), es algo que Valeriano, al igual que otros locales, han adquirido en los últimos años en sus reuniones en el CAO (Comité de Ayllus Originarios) ya sea de Chaquí o de Potosí, donde el discurso indianista que impera en Bolivia desde la llegada al poder de Evo Morales, ha calado profundamente. No obstante, a la pregunta de dónde aprendieron esos datos, todos afirman que también lo habían estudiado en la escuela.

19 El comunario que me llevó por primera vez a visitar el Churumayo, que es uno de los vecinos de Yawakata, tenía un gran interés por mostrarme las construcciones que allí había, y me señalaba, una y otra vez, que el material del que estaban construidas, era exclusivamente piedra.

20 Autoridad originaria máxima de la comunidad y del ayllu mayor, como ya se comentó. 
Del Churumayo, esos abuelos se fueron, poco a poco, bajando hacía la pampa. Como dice uno de los pocos habitantes actuales del Yawakata, «esos se han ya civilizado». Este coipaseño afirma que el resto de la comunidad ve como un atraso vivir en el cerro, principalmente por la incomodidad de los desplazamientos por el mismo, así como el estar alejado de la vida social y comunitaria, que en su mayoría se desarrolla en la parte del actual asentamiento ${ }^{21}$.

Y llegamos al Coipasi poblado actual. Una pequeña aldea andina, diseminada por una amplia zona llana, al pie de los cerros que parecen protegerla. Su configuración en ningún momento sigue un orden fijo. Se podría decir que gran parte de las casas (principalmente de Plaza Pata y Kelaque) se alinean a lo largo del camino que atraviesa el pueblo, primero de norte a sur y después de oeste a este (una especie de L). Pero posteriormente hay extensiones hacía otras partes del terreno, como sucede con Chaupicalle.

El centro social, como ya he mencionado, se encuentra en Plaza Pata, más concretamente en la escuela, que en esta zona de los Andes, al menos, funge un poco como el punto que vertebra la comunidad. La salida natural (para vehículos rodados, que es la que hoy prima) es hacia el norte, hacia la carretera nacional Sucre-Potosí que lleva al cercano centro poblacional de Betanzos e, incluso, hasta esas grandes ciudades. La parte más poblada y con mayor vida comunitaria es el sur, sin salida para vehículos, tan sólo caminos para ovejeras que llevan hasta la zona de Laqaya.

Sin entrar en más pormenores descriptivos del pueblo, quiero centrar el análisis en ese elemento que vengo comentado que los coipaseños usan como descriptor de su desarrollo: la estructura de las viviendas.

En Coipasi hay dos grandes fiestas. La primera, ya mencionada, es la patronal de San Pedro que se celebra el 29 de junio. Y la segunda, la que nos interesa aquí, es la del 9 de mayo, lo que los habitantes de la comunidad conocen por «aniversario del colegio». El 9 de mayo de 1953 el Doctor Víctor Montoya Medinacely puso en marcha el conocido como Proyecto Coipasi de Educación Fundamental (Instituto Indigenista Interamericano 1953; Montoya 1954). Fue un programa de educación y «transformación» de las comunidades quechuas de Potosí2 ${ }^{22}$, realizado por las conocidas como Escuelas de $\mathrm{Cristo}^{23}$, que tenía cinco ejes sobre los que giraba la labor educativa: salud, economía, hogar, ocio y mejora de conocimientos básicos (Considine 1970: 161). La estancia del profesor Montoya y su equipo ha sido convertida por los coipaseños en un hito histórico, es decir, en un evento que claramente, en la significación local, ha marcado un antes y un después de la comunidad (Hill 1988). Un

21 En realidad, el Yawakata está muy cercano al pueblo, apenas a unos dos minutos caminando. De hecho, desde la casa de este comunario hasta el centro de la vida social (la escuela) se tarda mucho menos tiempo que desde las casas más alejadas de la sección de Chawpi Kalle, ya en la pampa y considerado como asentamiento actual y civilizado. Los accesos son caminos bien construidos, aunque es cierto que en pendiente y, como en todos los Andes, se hacen más complicados de transitar en época de lluvias.

22 Un dato importante es que el doctor Víctor Montoya se formó en el CREFAL (Centro de Cooperación Regional para la Educación de Adultos en América Latina y el Caribe) de Pátzcuaro (México), uno de los primeros grandes centros de formación indigenista de América -creado en 1950- y que todavía hoy está en funcionamiento.

23 Creadas por el sacerdote José Zampa, nacieron en la ciudad de Potosí en 1907. Únicamente atendieron al principio a escuelas de mineros en la misma ciudad, pero en 1928 ya había 120 centros en diferentes provincias del Departamento de Potosí (Choque y Quisbert 2006: 140-141; Considine 1970: 160-161). 
acontecimiento que crea personajes, protagonistas y cuyas huellas en la comunidad son mostradas con entusiasmo a quien pregunte por su pasado. Pero, en realidad, de toda la labor del Doctor Víctor Montoya Medinacely -con el nombre completo, como se le menciona en la comunidad-, lo más recordado, con diferencia, es el «concurso de casas mejoradas».

Los coipaseños hablan de su comunidad en el pasado como un núcleo empobrecido y arcaico. Mencionan un atraso cultural que hoy ya ha sido superado. Superación que comenzó ese 9 de mayo de 1953. A lo largo de este trabajo, he ido mencionando cómo la forma de las casas de los diferentes asentamientos en el pasado, así como los materiales con los que están construidas, son un síntoma claro para hablar del paso del tiempo y del progreso comunitario. Y es en el actual hábitat y en la forma de sus casas, donde encontramos el mejor ejemplo de esta interpretación local.

Antes del «concurso de casas mejoradas», las viviendas eran como las del Churumayo, es decir, de piedras y de una sola estancia. Los miembros del equipo del doctor Montoya afirmaban que las condiciones de salubridad en las que vivían entonces los coipaseños, eran insoportables: «tenemos que encontrar un medio para hacer ver a estas personas lo miserables, feas y sucias que son sus casas» (Considine 1970: 163 [traducción propia] $)^{24}$. Y para ello, hablaban con los locales y les explicaban:

«¿Ve Joaquín? [decía el doctor]. Tú eres una persona alta. Pero la puerta de tu casa es tan baja y estrecha, que solo puedes pasar flexionándote y doblándote. En otros lugares, las personas construyen las puertas de su casa del tamaño que necesiten, y así no pierden su dignidad cada vez que uno quiere entrar a su propia casa.

‘¿Ve?', decía el Doctor, pasando su mano por la pared y caminando hacía la puerta, 'mira como mi mano se llena de hollín negro. La habitación donde vives y la cocina de tu mujer es tan pequeña (...) que la casa siempre está llena de hollín por el humo. La oscuridad es tanta por la acumulación del hollín, que no se puede ver la cantidad de suciedad que hay. Si nos dejaras abrir un hueco en las paredes de adobe y poner unas pequeñas ventanas, estarías encantado con la diferencia que habría dentro'» (Considine 1970: 163 [traducción propia]).

Consiguieron que tres familias hicieran mejoras en sus casas, ampliando las estancias, haciendo las puertas más grandes, incorporando ventanas y sustituyendo la piedra enteramente por el adobe. Se pusieron nuevos techos de pajas y se limpiaron suelos y $\operatorname{cocinas}^{25}$. El resultado provocó la indiferencia de algunos, la desconfianza de otros y la curiosidad y admiración de la mayoría (Considine 1970: 163).

Pero entonces, Víctor Montoya puso en marcha en 1956 el «concurso de casas mejoradas» del que todo el mundo habla 55 años después. Consiguió que gran parte de

24 El propio doctor Montoya indicaba que las condiciones en las que vivían los coipaseños no eran consecuencia de la pobreza, sino de «la falta total de estímulos para llevar a cabo una vida mejor. Hábitos muy enraizados han hecho a la gente indiferente al cambio, resignadas a vivir en las condiciones antihigiénicas de sus chozas de barro» (Considine 1970: 165 [traducción propia]).

25 Como afirmaba el propio Montoya, aunque se consiguió hacer cocinas nuevas, separadas de las habitaciones y con la estufa levantada del suelo, así como con chimenea de ventilación, éstas únicamente eran usadas por las parejas jóvenes, pues las ancianas las tenían de adorno y continuaban cocinando en los fogones tradicionales (Considine 1970: 164-165). Hoy en día, yo he podido comprobar que la mayor parte de las mujeres coipaseñas tienen cocinas a medio camino entre unas y otras, es decir, en un estancia separada pero con el fuego en el suelo y poca ventilación. 
la comunidad se implicara al traer jueces desde La Paz y convertir ese domingo en un día festivo (Considine 1970: 164). A partir de entonces parece ser que la forma constructiva de la comunidad cambió y todos se apuntaron a la mejora de sus viviendas, haciéndolas más grandes, más ventiladas y abandonando definitivamente las piedras.

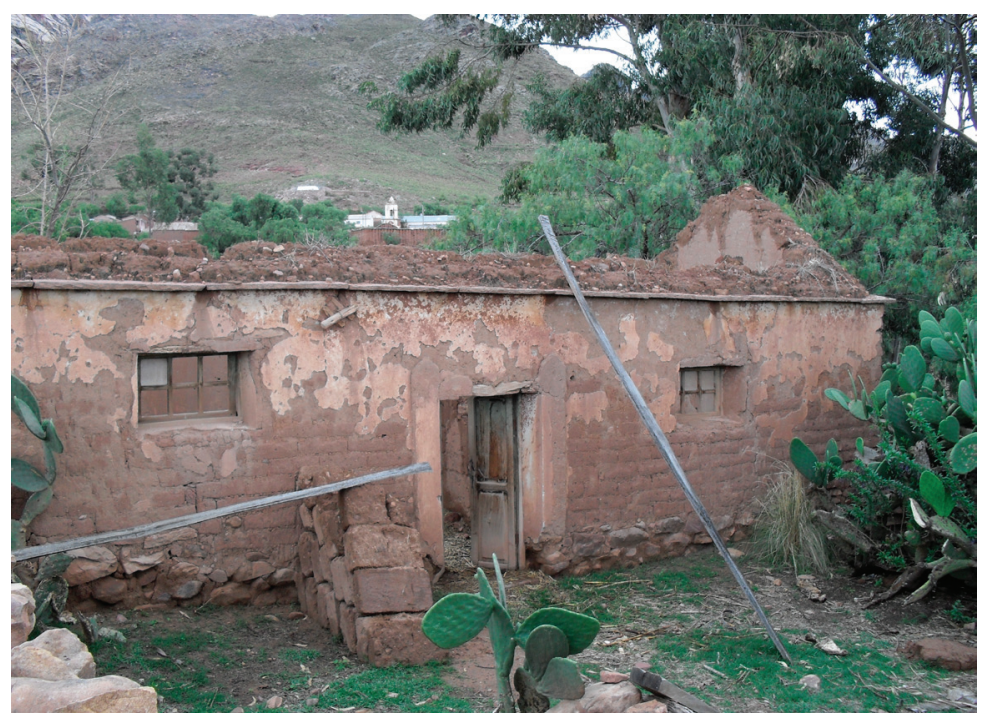

Figura 5: Casa resultado del concurso del profesor Víctor Montoya en 1956.

Hoy en Coipasi todo el mundo puede señalar cuáles son las casas que aun quedan de antes del concurso y cuáles son las que se mejoraron con éste (Figura 5). Te llevan a verlas y te indican cuáles son los principales cambios: las ventanas y el adobe.

«Más antes, la gente, nuestras casitas, no tenían ventana, no tenían asientos, así... cuando han dicho el Proyecto en esa fecha, concurso de casas mejoradas han organizado. Y ahí esas casitas han mejorado, han hecho ventanas, han hecho reboque con cal. Ese se llama Proyecto Coipasi. Cuando han reformado sus casas. Con premios han hecho ya» (Valeriano Huaranca).

«Antes, las casas, por ejemplo, también bien la hacen. Esas casas antiguas... esa casita que allí se está cayendo, estaba en el proyecto. Cada... la mayor parte de las casitas no tenían ni ventanita si quiera. Pura pared (...) Un agujerito y la puertita. Un poquito. Para construir, o para poner ese proyecto había un señor que se llamaba Víctor Montoya. Ese ha planteado el proyecto ese. Entonces, desde ese momento, empezamos a conocer, qué es el proyecto. Muchas cositas...muchas casitas, mejor dicho, como diez casas, ha construido...no él, sino con el mismo dueño ha hecho construir, con ventanitas. Mi casa, al otro ladito, tiene ventanas chiquitito. Ese, con él está. Entonces, el que ha hecho mejorcito, tenía premio. Premio, para uno ha sacado dos camisas. Hay otro que ha sacado parecido. Hay otro que ha sacado unos calentadorcitos para cocinar. Hay otros que han sacado unos bañadorcitos...entonces la gente se dio cuenta al momento. Empezamos a construir, ya con ventanas entonces. Pero le agradecemos también a ese caballero» (Fermín Relos). 
«Entonces eso enseñaban... maestros han venido y se han quedado. Entonces la gente ya un poquito empezó... porque las casitas, había un concurso de casas mejoradas eran pues. Ni tenían ventanas pues. No tenían ventanas. Nada pues. Entonces vivían, como las casas no eran, eran mal construidas, y así que vivían en, ¿como se llamaba?, levantaban paredes pura, de pura piedra, la untaban con barro así, y así nomás vivían. Y allí mismo era su comedor. Y allí mismo era su dormitorio. Y allí mismo se cocinaba y así vivían (...) Claro, y después y han venido los maestros y los maestros dijeron que tenía que haber un concurso de casas mejoradas. Tienen que poner puertitas, ventanas. Tienen que ser bien revocaditos, todo tiene que ser ligero pues (...)» (Guillermo Huaranca).

Muchos afirman que fue entonces cuando la comunidad mejoró, cambió y progresó. La llegada de la escuela, la mejora en las condiciones de vida como las casas, la llegada de luz unos años después. Todo ello fue el comienzo del cambio hacía una comunidad más desarrollada, menos arcaica. Porque como dice el mismo kuraka de la comunidad, «claro que nosotros un poquito con lo que es la escuela ya nos hemos civilizado». Y de las casas de adobe en los años cincuenta se ha ido pasando poco a poco a las de «materiales» (ladrillo y calamina): "Y ahora, ya no quieren vivir... digamos éste. Este es mi casa, pero antes, y ahora ya no quieren hacer de adobe pues, quieren hacer de puros materiales»».

En el asentamiento actual de Coipasi, por tanto, conviven diferentes tiempos y acontecimientos que son recordados, entre otras cosas, por la forma de las viviendas y por los materiales usados para ello. En el Churumayo lo hacen con el resto de viviendas construidas exclusivamente con piedras y de una sola estancia. En el pueblo actual conviven las anteriores al Proyecto Coipasi, todas ellas deshabitadas; las que surgieron del proyecto, de adobe y techos de paja - de las cuales, todavía algunas están en uso-; y algunas de las actuales construidas ya con materiales. La mayoría de las casas habitadas de Coipasi siguen siendo, no obstante, de adobe, aunque con lo que ellos consideran mejoras: bien encaladas, techos de calamina y de dos pisos.

\section{Reflexiones finales}

Que los lugares asociados a un acontecimiento del pasado, así como las características atribuidas a estos, son usados por la memoria para registro y mantenimiento del recuerdo y del acontecimiento en sí, es algo que ha pasado a ser un lugar común en las Ciencias Sociales (por ejemplo, Auge 2003; Cohn 1981: 249 y ss; Le Goof 1992: 58; Rappaport 1994: 88). Coipasi parece mostrarnos que no únicamente el recuerdo queda grabado en la piedra, sino que también es reforzado por la clase de piedra que es, el uso que se hace de la misma y los restos que hoy podemos encontrar. Es decir, es una lectura holística del lugar y de su significado.

En la concepción local del paso del tiempo y del desarrollo de la comunidad, se juega con la lectura del territorio y, más concretamente, con los lugares donde alguna vez ha estado el pueblo, ya sea el mismo, es decir, el ocupado por los coipaseños aunque sea antiguamente; ya sean ajenos, ocupados por una humanidad anterior (chullpas) o por un grupo de personas lejanos en el espacio y en el tiempo (llameros). 
El coipaseño se ubica actualmente en el tiempo y en el espacio en relación con su comunidad. Dónde está asentada y qué características tiene. Ya no únicamente en cuanto a división en secciones o en partes, sino también respecto a la estructura y características de las viviendas. Se comparan éstas con las que el tiempo ha dejado en ruinas, con las que el acontecimiento ha ido abandonado, y con las que la interpretación local ha ido creando.

Sienten que tras el «concurso de casas mejoradas» la comunidad cambió, «ya nos hemos civilizado», pues aparte de la llegada de la escuela de una forma ya consolidada, se cambiaron ciertos hábitos de vida con los que vivían peor de lo que lo hacen ahora. El principal de estos es la vivienda. Por eso, los coipaseños, se afanan por enseñarte cómo eran las anteriores, para que uno mismo pueda compararlas con las actuales. Te llevan hasta el Churumayo para que se pueda apreciar cómo vivían antes en el cerro y en casitas pequeñas de piedra y barro. Y te muestran con sorpresa y curiosidad cómo los chullpas pudieron vivir en el Vizcachas Wasi, entre cuevas, aperturas pequeñas y despensa de alimentos colgados de la pared rocosa.

Las huellas del tiempo en el espacio funcionan entonces como marcadores de recuerdo y de definición cultural. Son según cómo viven y cómo vivían en el pasado. Reconocen así el paso del tiempo y definen un desarrollo hacia lo que ellos consideran un estado mejor. Rastrear el pasado, los acontecimientos, los asentamientos del grupo y las características de aquellos lugares donde vivían y viven, se convierte, así, en forma de explicarse en el presente y de comprender su pasado.

\section{Referencias bibliográficas}

Abercrombie, Thomas A.

2006 Caminos de la memoria y del poder. Etnografia e historia en una comunidad andina [1998]. La Paz: IFEA - IEB - Asdi.

Allen, Catherine J.

1994 «Time, Place and Narrative in an Andean Community». Bulletin de la Société Suisse des Américanistes 57-58: 89-95.

ARNOLD, Denise Y.

1998 «La casa de adobes y piedras del Inka. Género, memoria y cosmos en Qaqachaka», en Hacia un orden andino de las cosas, Denise Y. Arnold et al., pp. 31-108. La Paz: Hisbol - ILCA.

Astvaldsson, Astvaldur

2000 Las voces de las wak'a. Fuentes principales del poder político aymara. La Paz: CIPCA.

Augé, Marc

1998 Los no lugares. Espacio del anonimato. Una antropología de la sobremodernidad. Barcelona: Gedisa.

2003 El tiempo en ruinas. Barcelona: Gedisa.

Bouysse-Cassagne, Thérèse

1987 La identidad aymara. Aproximación histórica (Siglo XV, Siglo XVI). La Paz: Hisbol - IFEA. 
Bouysse-Cassagne, Thérèse y Olivia Harris

1987 «Pacha: en torno al pensamiento aymara», en Tres reflexiones sobre el pensamiento aymara, T. Bouysse-Cassagne et al., pp. 11-60. La Paz: Hisbol.

Choque CAnqui, Roberto y Cristina Quisbert QuisPe

2006 Educación indigenal en Bolivia. Un siglo de ensayos educativos y resistencias patronales. La Paz: Unidad de Investigaciones Históricas - Ibis.

CoHN, Bernard

1981 «Toward a Rapprochement». Journal of Interdisciplinary History 12(2): 227-252.

Considine, John J.

1970 New Horizons in Latin America [1958]. Salem: Ayer Publishing.

Cruz, Pablo

2005 «El lado oscuro del mundo. Una cartografía de la percepción de los sitios arqueológicos en los Andes meridionales. (Laguna Blanca, Catamarca-Argentina, y Potosí, Bolivia)». Boletín de la Sociedad de Investigación del Arte Rupestre de Bolivia 19: 38-48.

2006 «Mundos permeables y espacios peligrosos. Consideraciones acerca de punkus y qaqas en el paisaje altoandino de Potosí, Bolivia». Boletín del Museo Chileno de Arte Precolombino 11(2): 35-50.

Dillon, Mary y Thomas Abercrombie

1988 «The Destroying Christ: An Aymara Myth of Conquest», en Rethinking History and Myth. Indigenous South American Perspectives on the Past, Jonathan D. Hill, ed., pp. 50-77. Chicago: University of Illinois Press,

Gil García, Francisco M.

2005 «Batallas del pasado en tiempo presente. 'Guerra antigua', civilización y pensamiento local en Lípez (dpto. de Potosí, Bolivia)». Bulletin de L’Institut Français d'Études Andines 34 (2): 197-220.

Gose, Peter

1991 «House Rethatching in an Andean Annual Cycle: Practice, Meaning, and Contradiction». American Ethnologist 18 (1): 39-66.

Guaman Poma de Ayala, Felipe

1980 Nueva Coronica y Buen Gobierno. Vol. 1. Caracas: Biblioteca Ayacucho.

GutiÉrRez Estévez, Manuel

2010 «Esos cuerpos, esas almas. Una introducción», en Retóricas del cuerpo amerindio, Manuel Gutiérrez Estévez y Pedro Pitarch, eds., pp. 9-55. Madrid: Iberoamericana-Vervuert.

HiLl, Jonathan D.

1988 «Introduction», en Rethinking History and Myth. Indigenous South American Perspectives on the Past, Jonathan D. Hill, ed., pp. 1-17. Chicago: University of Illinois Press.

INSTITUTO INDIGENISTA INTERAMERICANO

1953 «Proyecto ‘Coipasi’ de Educación Fundamental». Boletín Indigenista 13 (3): 234-237.

LE Goff, Jacques

1992 History and Memory. Nueva York: Columbia University Press. 
Montoya Medinacely, Víctor

1954 «Informe del Proyecto ‘Coipasi’ de Educación Fundamental: 1953». Boletín Indigenista 14 (1): 14-25.

Murra, John V.

1975 «El control vertical de un máximo de pisos ecológicos en la economía de las sociedades andinas» [1972], en Formaciones económicas y políticas del mundo andino, pp. 59-115. Lima: Instituto de Estudios Peruanos.

2002 El mundo andino: población, medio ambiente y economía. Lima: Instituto de Estudios Peruanos - Pontificia Universidad Católica del Perú.

Nicolas, Vicent, Sandra Zegarra y Alfredo Puma (recops.)

2004 Ayllusninchismanta parlarispa. Antología de historias orales de Tinkipaya. La Paz: PIEB.

Ochoa Villanueva, Víctor

1976 «Ritos para la construcción de la casa». Instituto de Estudios Aymaras. Boletín Ocasional 36: 1-20.

Platt, Tristan

1986 «Mirrors and Maize: The Concept of Yanantin among the Macha of Bolivia», en Anthropological History of Andean Polities, J. V. Murra, N. Wachtel y J. Revel, eds., pp. 228-259. Cambridge: Cambridge University Press.

RAPPAPORT, Joanne

1994 «Geography and Historical Understanding in Indigenous Colombia», en Who Needs the Past? Indigenous Values and Archaeology, R. Layton, ed., pp. 84-94. Londres: Routledge.

RASNAKE, Roger

1988 «Images of Resistance to Colonial Domination», en Rethinking History and Myth. Indigenous South American Perspectives on the Past, Jonathan D. Hill, ed., pp. 136-156. Chicago: University of Illinois Press.

RAVINES, Roger

1978 «Edificación y vivienda», en Tecnología andina, R. Ravines, comp., pp. 557-571. Lima: Instituto de Estudios Peruanos.

Stolen, Ann Laura

2009 Along the Archival Grain. Epistemic Anxieties and Colonial Common Sense. Princenton: Princenton University Press.

URTON, Gary

1988 «La arquitectura pública como texto social: la historia de un muro de adobe en Pacatiqtambo, Perú (1915-1985)». Revista Andina 31 (1): 225-261.

WACHTEL, Nathan

2001 El regreso de los antepasados. Los indios urus de Bolivia, del siglo XX al XVI. México: El Colegio de México - Fideicomiso Historia de las Américas - Fondo de Cultura Económica. 